RELATIONSHIP BETWEEN SERUM FERRITIN LEVEL AND ATTENTION DEFICIT HYPERACTIVITY DISORDER IN CHILDREN ATTENDING ALEXANDRIA UNIVERSITY CHILDREN'S HOSPITAL

Tarek El-Sayed Ismail Omar, Mona Khalil Mohamed, Marwa Saeed AbdElmaksoud, Nehal Hamdy Mohamed Ibrahim

Department of Pediatrics, Faculty of Medicine, University of Alexandria.

\begin{tabular}{|l|}
\hline Introduction \\
\hline $\begin{array}{l}\text { Attention-deficit / hyperactivity disorder (ADHD) is the most common } \\
\text { neurobehavioral disorder in childhood. Its prevalence in children and } \\
\text { adolescents is around } 5.3 \% \text { worldwide. ADHD is characterized by persistent } \\
\text { patterns of inattention, hyperactivity and impulsivity that affects multiple } \\
\text { domains of life cause significant functional impairment. ADHD imposes various } \\
\text { kinds of pressures on families and communities. ADHD is attributed to the } \\
\text { interplay of social, environmental, neurobiological, and genetic factors. Iron is } \\
\text { essential for many important biological processes. It functions as a cofactor in } \\
\text { the metabolism of many neurotransmitters like dopamine. Its deficiency plays a } \\
\text { role in ADHD pathogenesis. Serum ferritin is a reliable indicator of iron storage in } \\
\text { tissues such as the brain. }\end{array}$ \\
\hline
\end{tabular}

\section{Aim of the work}

We aimed to study serum ferritin levels in children with ADHD, and the relationship between it and the severity of the disease.

\section{Subjects and Methods}

This case-control study was conducted on (100) children aged from six to twelve years ( 50 children diagnosed with ADHD based on DSM- 5 diagnostic criteria and were recruited from Pediatric Neurodevelopmental outpatient clinic of Alexandria University Children Hospital Smouha "group I" and 50 sex and agematched siblings of group I who are not fulfilling the DSM-5 diagnostic criteria of ADHD as a controls " group II")

Children who had Conditions that affect serum ferritin level like chronic liver disease, non-iron deficiency anemia, acute and chronic inflammation, infections or on iron therapy for three months were excluded from our study.

The parent(s) of the children of both groups were subjected to complete history taking and Children of both groups were subjected to Complete clinical examination, Complete blood counts and measure of serum ferritin level. Children with ADHD were subjected to Psychometric studies (Arabic Version of Conner's Parent Rating Scale-Revised CPRS-R, The Arabic version of "Stanford Binet intelligence test - 4 th edition for assessment of Intelligence Quotient)

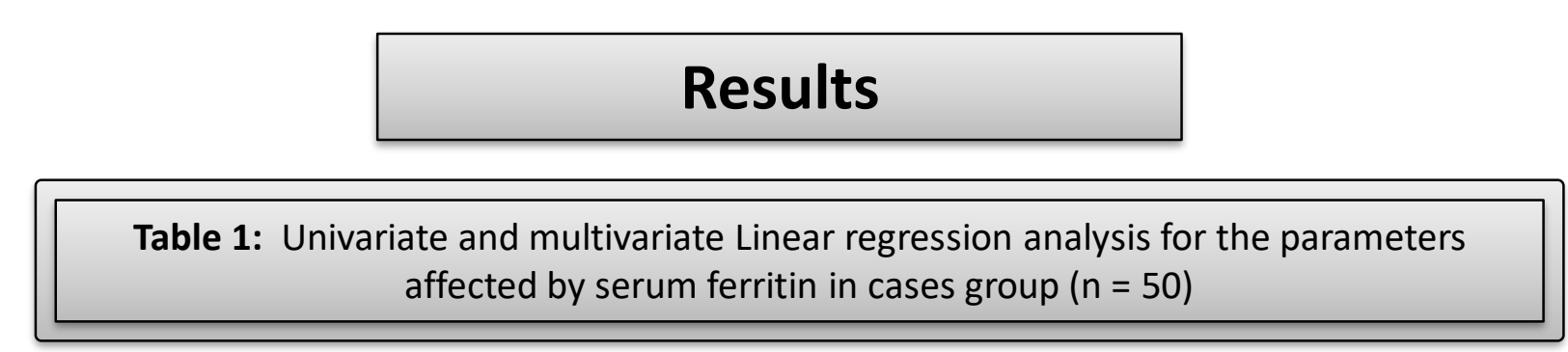

\begin{tabular}{|c|c|c|c|c|}
\hline & \multicolumn{2}{|c|}{$\begin{array}{l}\text { Univariate } \\
\end{array}$} & \multicolumn{2}{|c|}{ 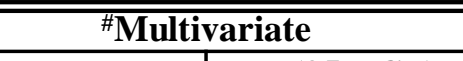 } \\
\hline & $\mathbf{P}$ & B (95\%C.I) & $\mathbf{p}$ & B (95\%C.I) \\
\hline Total IQ & $<0.001^{*}$ & $\begin{array}{c}0.443 \\
(0.261-0.624)\end{array}$ & $<0.001^{*}$ & $\begin{array}{c}0.367 \\
(0.212-0.523)\end{array}$ \\
\hline Hyperactivity & $<0.001^{*}$ & $\begin{array}{c}-0.430 \\
(-0.64--0.22)\end{array}$ & 0.622 & $\begin{array}{c}0.084 \\
(-0.257-0.424)\end{array}$ \\
\hline ADHD index & $<0.001^{*}$ & $\begin{array}{c}-0.683 \\
(-0.95-0.42)\end{array}$ & 0.187 & $\begin{array}{c}-0.223 \\
(-0.558-0.113)\end{array}$ \\
\hline $\begin{array}{l}\text { Inattentive conner's } \\
\text { scale severity }\end{array}$ & $<0.001^{*}$ & $\begin{array}{c}-0.543 \\
(-0.80--0.29)\end{array}$ & 0.675 & $\begin{array}{c}-0.108 \\
(-0.625-0.409)\end{array}$ \\
\hline $\begin{array}{l}\begin{array}{l}\text { Total conner's scale } \\
\text { severity }\end{array} \\
\end{array}$ & $<0.001^{*}$ & $\begin{array}{c}-0.612 \\
(-0.84--0.39) \\
\end{array}$ & 0.056 & $\begin{array}{c}-0.548 \\
(-1.111-0.016) \\
\end{array}$ \\
\hline Opposition & $0.001^{*}$ & $\begin{array}{c}-0.316 \\
(-0.49--0.14)\end{array}$ & 0.917 & $\begin{array}{c}-0.013 \\
(-0.257-0.232)\end{array}$ \\
\hline Cognitive problems & $0.001^{*}$ & $\begin{array}{c}-0.441 \\
(-0.70--0.18)\end{array}$ & 0.693 & $\begin{array}{c}0.071 \\
(-0.292-0.434)\end{array}$ \\
\hline $\begin{array}{l}\text { Presentations of } \\
\text { ADHD }\end{array}$ & $0.002^{*}$ & $\begin{array}{c}-5.709 \\
(-9.12--2.30) \\
\end{array}$ & 0.992 & $\begin{array}{c}-0.022 \\
(-4.452-4.409) \\
\end{array}$ \\
\hline $\begin{array}{l}\text { Associated } \\
\text { comorbidity }\end{array}$ & $0.004^{*}$ & $\begin{array}{c}-9.935 \\
(-16.47--3.40) \\
\end{array}$ & 0.520 & $\begin{array}{c}-2.146 \\
(-8.828-4.536) \\
\end{array}$ \\
\hline $\begin{array}{l}\text { Receiving ADHD } \\
\text { drugs }\end{array}$ & $0.006^{*}$ & $\begin{array}{c}-8.313 \\
(-14.18--2.44)\end{array}$ & 0.396 & $\begin{array}{c}3.019 \\
(-4.095-10.133\end{array}$ \\
\hline Social problems & $0.021^{*}$ & $\begin{array}{c}-0.205 \\
(-0.38--0.03) \\
\end{array}$ & 0.587 & $\begin{array}{c}0.053 \\
(-0.143-0.249) \\
\end{array}$ \\
\hline School performance & 0.066 & $\begin{array}{c}-0.03 \\
3.423 \\
(-0.24-7.08)\end{array}$ & & \\
\hline Age (years) & 0.071 & $\begin{array}{c}-1.280 \\
(-2.67-0.12)\end{array}$ & & \\
\hline Tension/shyness & 0.425 & $\begin{array}{c}-0.082 \\
(-0.29-0.12)\end{array}$ & & \\
\hline $\begin{array}{l}\text { Psychosomatic } \\
\text { disorder }\end{array}$ & 0.569 & $\begin{array}{c}-0.054 \\
(-0.25-0.14)\end{array}$ & & \\
\hline Socioeconomic status & 0.658 & $\begin{array}{c}0.927 \\
(-3.25-511)\end{array}$ & & \\
\hline Gender & 0.756 & $\begin{array}{c}-1.048 \\
(-7.79-569)\end{array}$ & & \\
\hline
\end{tabular}

Table 2: Correlation between serum ferritin and Conner's scale severity in cases group $(n=50)$

\begin{tabular}{||l|c|c|}
\hline \multirow{2}{*}{ Conner's Scale Severity } & \multicolumn{2}{|c|}{ Serum ferritin } \\
\cline { 2 - 3 } & $\mathbf{r}_{\mathrm{s}}$ & $\mathbf{P}$ \\
\hline Opposition & $-0.468^{*}$ & $0.001^{*}$ \\
\hline Cognitive problems & $-0.423^{*}$ & $0.002^{*}$ \\
\hline Hyperactivity & $-0.491^{*}$ & $<0.001^{*}$ \\
\hline Tension/shyness & -0.042 & 0.770 \\
\hline Social problems & $-0.329^{*}$ & $0.020^{*}$ \\
\hline Psychosomatic disorder & -0.109 & 0.453 \\
\hline ADHD index & $-0.605^{*}$ & $<0.001^{*}$ \\
\hline Inattentive & $-0.532^{*}$ & $<0.001^{*}$ \\
\hline Hyperactive & $-0.535^{*}$ & $<0.001^{*}$ \\
\hline Conner's scale severity total & $-0.596^{*}$ & $<0.001^{*}$ \\
\hline \hline
\end{tabular}

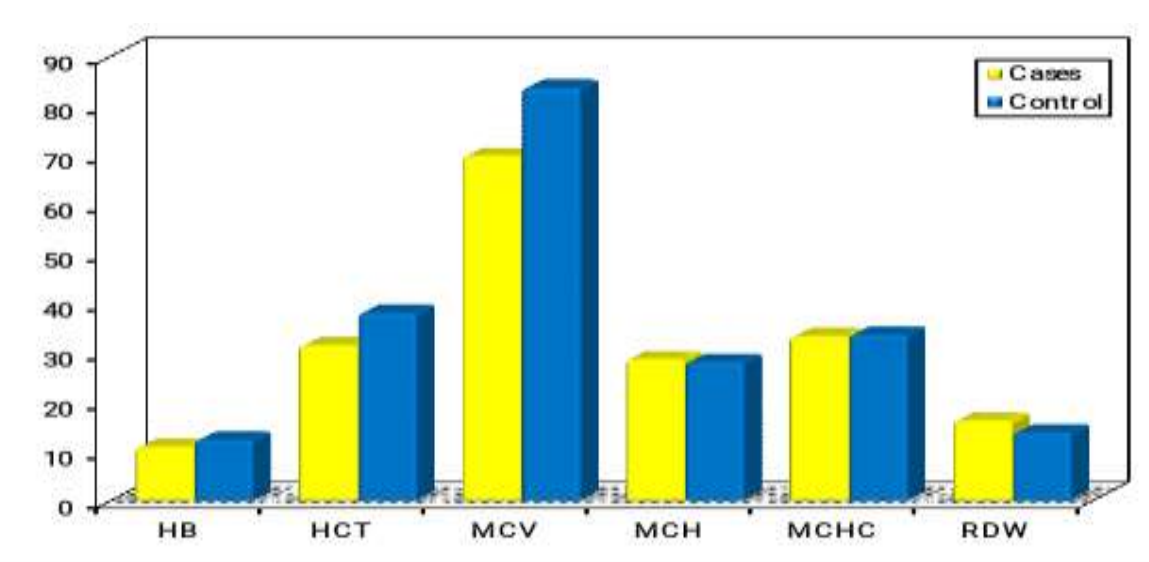

Figure: Comparison between the two studied groups according to $C B C$

\section{Conclusion}

the findings of the current study suggest that preventing iron deficiency by a balanced nutritional diet and may-be iron supplement might have a protective role not only against ADHD also for less severe core symptoms.

2019@Alexandria Faculty of Medicine
CC-BY-NC

